\title{
Determination of Coherency and Rigidity Temperatures in Al-Cu Alloys Using In Situ Neutron Diffraction During Casting
}

\author{
JEAN-MARIE DREZET, ${ }^{1,3}$ BASTIEN MIREUX, ${ }^{1}$ ZOLTAN SZARAZ, ${ }^{2}$ \\ and THILO PIRLING ${ }^{2}$ \\ 1.-Computational Materials Laboratory, Ecole Polytechnique Federale Lausanne, Lausanne \\ CH-1015, Switzerland. 2.-Institut Laue Langevin, Salsa instrument, Grenoble 38042, France. \\ 3.-e-mail: jean-marie.drezet@epfl.ch
}

The rigidity temperature of a solidifying alloy is the temperature at which the solid phase is sufficiently coalesced to transmit tensile stress. It is a major input parameter in numerical modeling of solidification processes as it defines the point at which thermally induced deformations start to generate internal stresses in a casting. This temperature has been determined for an Al-13 wt.\% $\mathrm{Cu}$ alloy using in situ neutron diffraction during casting in a dog-bone-shaped mold. This setup allows the sample to build up internal stress naturally as its contraction is not possible. The cooling on both sides of the mold induces a hot spot at the middle of the sample that is irradiated by neutrons. Diffraction patterns are recorded every $11 \mathrm{~s}$ using a large detector, and the very first change of diffraction angles allows for the determination of the rigidity temperature. We measured rigidity temperatures equal to $557^{\circ} \mathrm{C}$ and $548^{\circ} \mathrm{C}$ depending on the cooling rate for grain refined $\mathrm{Al}-13 \mathrm{wt} . \% \mathrm{Cu}$ alloys. At a high cooling rate, rigidity is reached during the formation of the eutectic phase. In this case, the solid phase is not sufficiently coalesced to sustain tensile load and thus cannot avoid hot tear formation.

\section{INTRODUCTION}

Coalescence corresponds to the formation of solid bridges between grains when both solid and liquid phases are percolated. ${ }^{1}$ As such, it represents a key transition in the solidification of metallic alloys. Coalescence starts at the coherency point when the grains begin to touch each other but are unable to sustain any tensile loads. Rappaz et al. ${ }^{2}$ have used the concept of disjoining pressure used in fluid dynamics to establish a theoretical framework for the coalescence of primary phase dendritic arms within a single grain or at grain boundaries. For pure substances, approaching planar liquid/solid interfaces coalesce to a grain boundary at an undercooling $\Delta T_{\mathrm{b}}$ given by:

$$
\Delta T_{\mathrm{b}}=\frac{\gamma_{\mathrm{gb}}-2 \gamma_{\mathrm{sl}}}{\Delta S_{\mathrm{f}}} \frac{1}{\delta}
$$

where $\delta$ is the thickness of the solid-liquid interface, $\gamma_{\mathrm{gb}}$ is the grain boundary energy, $\gamma_{\mathrm{sl}}$ is the solid-liquid interfacial energy, and $\Delta S_{\mathrm{f}}$ is the entropy of fusion. The quantity $\gamma_{\mathrm{gb}}-2 \gamma_{\mathrm{sl}}$ depends on the grain misorientation. When it is positive, the two liquid-solid interfaces are "repulsive." In this case, a stable liquid film between adjacent dendrite arms located across such grain boundaries can remain until the undercooling exceeds $\Delta T_{\mathrm{b}}$. For alloys, coalescence is also influenced by the concentration of the solute elements in the liquid films. The temperature and concentration of the liquid films must reach a coalescence line parallel to, but $\Delta T_{\mathrm{b}}$ below, the liquidus line before coalescence can occur. At the macroscopic level, i.e., at the level of many randomly oriented grains, coalescence must be considered as a transition that takes place between coherency (first contact between the grains) and rigidity (ability to transmit tensile strains and stresses). If coalescence between some grains is retarded, i.e., finishes at lower temperatures, the mushy structure becomes particularly sensitive to hot tearing or solidification cracking. ${ }^{3}$ This defect is a spontaneous failure of semi-solid metallic alloys that results in an intergranular fracture profile. It appears during casting near the end of solidification, 
especially in low solute content alloys where straining becomes localized and local liquid permeability is very low. At the macroscopic level, coalescence ends at the rigidity point, also called mechanical coherency, when the structure is able to sustain substantial tensile strains and stresses, i.e., when the solid phase is sufficiently percolated. The rigidity temperature is important as it determines the very instant macroscopic stresses start to build up owing to thermally induced deformations. ${ }^{4}$

The mechanical behavior of alloys in the mushy state has recently been intensively studied using $\mathrm{x}$-ray microtomography. In one study, in situ tensile test experiments were performed by Terzi et al. ${ }^{5,6}$ on alloys in the mushy state at the x-ray synchrotron of the European Synchrotron Radiation Facility (ESRF). The major drawbacks of such in situ tensile tests are that they are carried out in isothermal conditions, and not during cooling, because x-ray microtomography imaging requires time for image acquisition and the liquid state cannot be investigated owing to the rotations required for imaging. ${ }^{7}$ Moreover, the exact mechanical loading within the material is not known as the deformation, localized in the hottest part of the specimen, is not measured. These tests are currently limited to $\mathrm{Al}-\mathrm{Cu}$ alloys ${ }^{8}$ to get a good contrast between the liquid and solid phases, and the alloy is tested after heating to the correct temperature within the solidification interval and not during solidification from the fully liquid state. The last point is particularly detrimental as solidifying microstructures are different from those obtained after heating owing to dendrite coarsening and redistribution of solute elements. ${ }^{9}$ Fallet et al. ${ }^{10}$ studied the influence of a barium addition to $\mathrm{Al}-\mathrm{Cu}$ alloys on the morphology of liquid films in the mushy zone and showed that barium improves wetting of the solid phase by the liquid (decrease of $\gamma_{\mathrm{sl}}$ in Eq. 1) and thus delays coalescence of the grains. Tensile and shear tests were carried out during solidification, and it was observed that the presence of Ba most affects the fracture stress in tension at the very end of solidification. This is due to the delayed coalescence of Ba-treated alloys for which liquid films embrittle the alloy in tension up to very high solid fractions.

To our knowledge, in situ studies of stress accumulation in solidifying metals have been very limited, with only one unpublished study reported on cast aluminum composite structures. This study has shown that neutron diffraction at high flux sources is particularly well suited for such investigations as it would allow determining the very moment when strains and stresses appear in the mushy alloy. Although badly assessed, the rigidity temperature is a key parameter in solidification. It highly varies from one alloy to another and depends on both the cooling rate and the degree of grain refinement, i.e., on the grain structure such as equiaxed, columnar, globulitic, or globular. It is an important input data in numerical modeling of as-cast residual stresses in billets $^{11,12}$ and in rolling sheet ingots ${ }^{13}$ as it dictates the temperature below which thermal strains start to occur.

In the present study, neutron diffraction has been performed in situ during solidification. Rigidity temperature has been measured at the Salsa neutron diffractometer ${ }^{14}$ in $\mathrm{Al}-\mathrm{Cu}$ alloys under various cooling regimes in a dog-bone-shaped mold where solidification and tensile straining are concomitant.

\section{IN SITU NEUTRON DIFFRACTION DURING CASTING}

$\mathrm{Al}-13$ wt.\% $\mathrm{Cu}$ alloys were prepared by melting $\mathrm{Al}-4.43$ wt.\% $\mathrm{Cu}$ alloy and pure copper in an alumina crucible at $750^{\circ} \mathrm{C}$. The alloys were then grain refined with 0.4 wt. $\% \mathrm{Al}^{-\mathrm{TiB}_{2}}$ master alloy, cast in a dog-bone-shaped mold, and cooled at the extremities using air or water to achieve different cooling rates. The setup, shown in Fig. 1, is usually used to study the hot tearing susceptibility of new alloys. A hot spot forms at the center of the casting, and its axial contraction is prevented by the steel mold surrounding the central part. The thermal contraction of the solidifying material is constrained and stresses develop at the hot spot, and this may lead to hot cracking. The major advantage of this configuration is that solidification and tensile straining are concomitant. It is possible to control the amount of constraint on the hot spot by modulating cooling of the mold extremities and by preheating the mold.

To measure the accumulation of strain and thus of stress during casting, the lattice spacing was measured in situ at the hot spot location using neutron diffraction. Small holes were machined in the steel mold to provide unimpeded access to the sample for the neutron beam. Insulating alumina muffles were used to avoid liquid metal leakage. Type $\mathrm{K}$ thermocouples placed at precise locations within the casting allowed linking the temperature within the gage volume with the formation and shift of the (311) primary phase (i.e., Al-Cu solid solution) diffraction peak during solidification, which permitted the measurement of rigidity temperature. The experiments were carried out with a gauge volume of $2 \times 2 \times 15 \mathrm{~mm}^{3}$, using an open slit along gravity, and a casting cross section of $15 \times 25 \mathrm{~mm}^{2}$. Preliminary measurements carried out with the classic neutron detector at Salsa on Al-Cu 1.5 wt.\% are presented in Fig. 2 with temperature decreasing from $670^{\circ} \mathrm{C}$ down to room temperature. They appeared to show much promise as both the Al-Cu solid solution and the $\mathrm{Al} 2 \mathrm{Cu}$ peaks were clearly detected and exhibited a shift during solidification and cooling owing to the mold constraints. The casting did not present any hot tears, and one diffraction peak was recorded roughly every $25 \mathrm{~s}$ during casting. Nevertheless too few diffraction peaks were recorded above the eutectic temperature, $548^{\circ} \mathrm{C}$, of the $\mathrm{Al}-\mathrm{Cu}$ system, and thus the coherency 


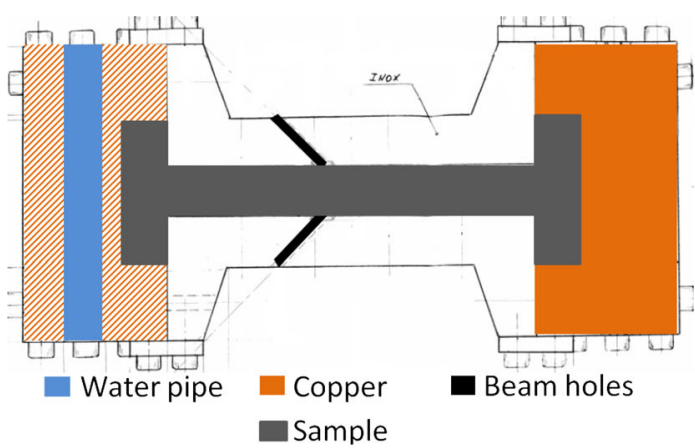

(a)

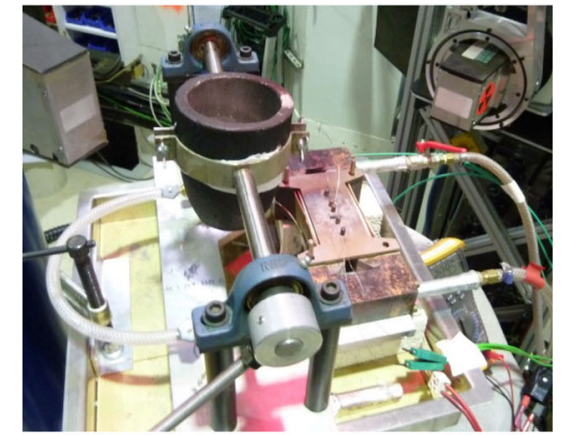

(b)

Fig. 1. (a) Dog-bone-shaped mold design (top view) with the two beam holes within the mold to avoid neutron absorption by steel; (b) experimental setup showing the instrumented mold and rotating crucible holder, ready for use in the neutron hutch.

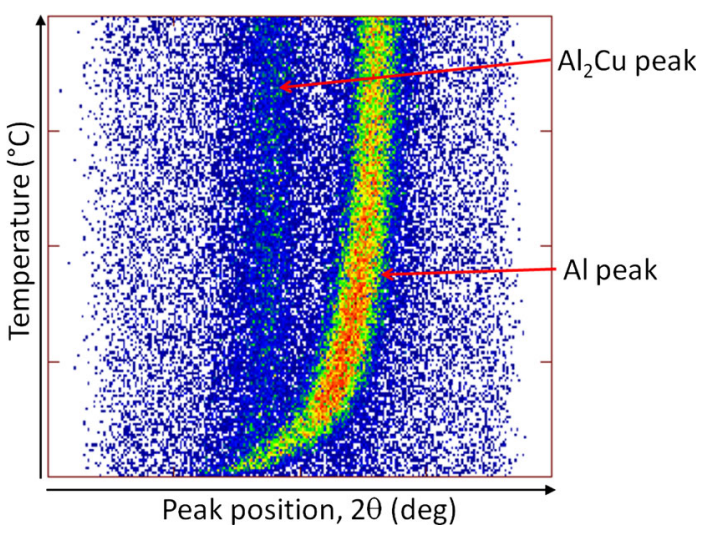

Fig. 2. Peak position versus time (or temperature) during solidification and cooling in an Al-Cu 1.5 wt.\% dog-bone-shaped casting. Both peak shifts are associated with the stress increase imposed by the mold constraints.

and rigidity temperatures could not be determined. To solve this issue, a large ion chamber neutron detector $\left(2 \mathrm{D}\right.$ position sensitive, $260 \times 260 \mathrm{~mm}^{2}$ active area with a $1-\mathrm{mm}$ resolution, $256 \times 256$ channels) was used in a second study. It allowed for the acquisition of exploitable peaks within $5 \mathrm{~s}$. With roughly $6 \mathrm{~s}$ between acquisitions, one diffraction peak was recorded roughly every $11 \mathrm{~s}$ during casting. As the alloy was grain refined, no texture appeared. Results using this large ion chamber neutron detector are presented hereafter.

\section{RESULTS}

Figure 3 shows the evolution of both the temperature at the hot spot and the diffraction angle of the $\mathrm{Al}-\mathrm{Cu}$ solid solution for two samples cast with two different cooling rates. Sample 1 was cooled rapidly with a solidification time of approximately $40 \mathrm{~s}$. It exhibited some hot tears at the hot spot, but it did not fully fracture. Sample 2 was cooled slowly (solidification time of approximately $100 \mathrm{~s}$ ) and was sound, i.e., free of hot tears. Solidification starts at $623^{\circ} \mathrm{C}$ with no undercooling, as the alloy is grain

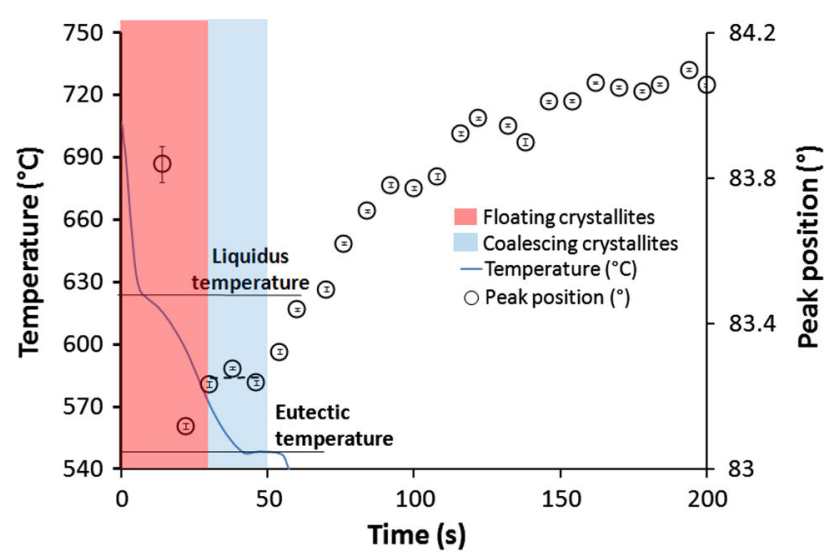

(a)

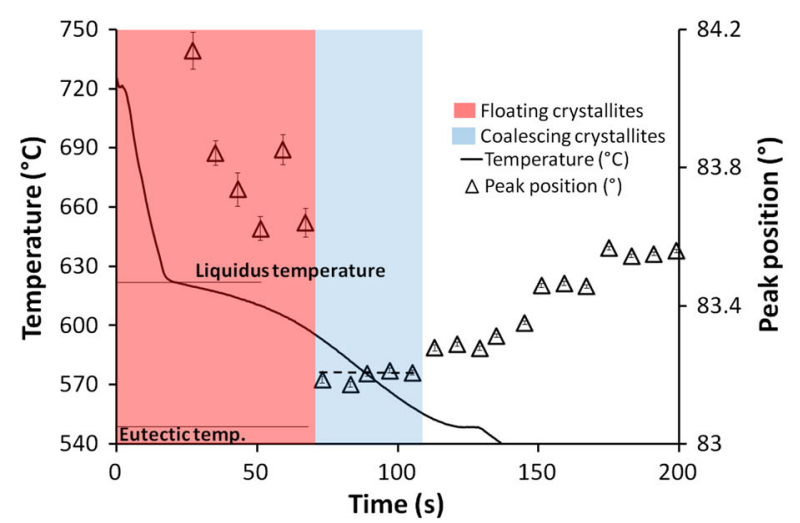

(b)

Fig. 3. Temperature in gage volume and peak position in (a) Sample 1 and (b) Sample 2.

refined. This liquidus temperature corresponds to a 13 wt. $\% \mathrm{Cu}$ content. Solidification ends at the eutectic temperature, $548^{\circ} \mathrm{C}$. Copper diffuses very slowly in solid aluminum, and thus, the evolution in volume fraction of solid can be calculated using Scheil's equation. With this equation, solidification ends at $548^{\circ} \mathrm{C}$ with the formation of the eutectic phase, $26 \%$ in volume fraction, independently of the cooling rate. Figure 4 shows both the evolution of 
the solid volume fraction at the hot spot and the measured diffraction angle for the two samples.

As shown in the figures, the very first peaks have erratic angle values with relative angular error higher than $10 \%$. They correspond to the diffraction of neutrons by crystallites floating freely in the liquid phase. The peaks then exhibit better quality with a relative angular error lower than $2 \%$, and their positions stabilize over three peaks in Sample 1 cast rapidly ( $40 \mathrm{~s}$ solidification time) and five peaks in Sample 2 cast with a lower cooling rate (100 s solidification time) when grains touch each other and start to coalesce. The rotation and displacement of the grains are constrained, but tensile stress still cannot be transmitted. The temperature at this instant is considered as the coherency temperature and corresponds to the beginning of the coalescence transition. The exact determination of

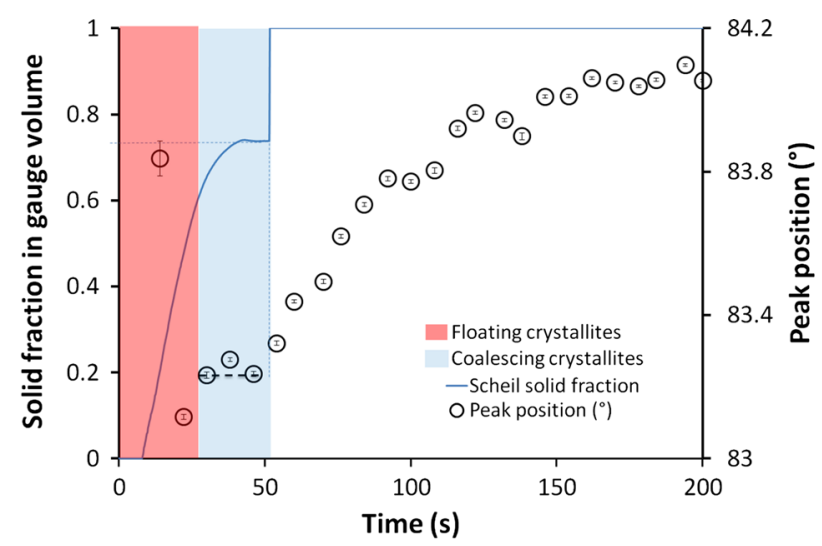

(a)

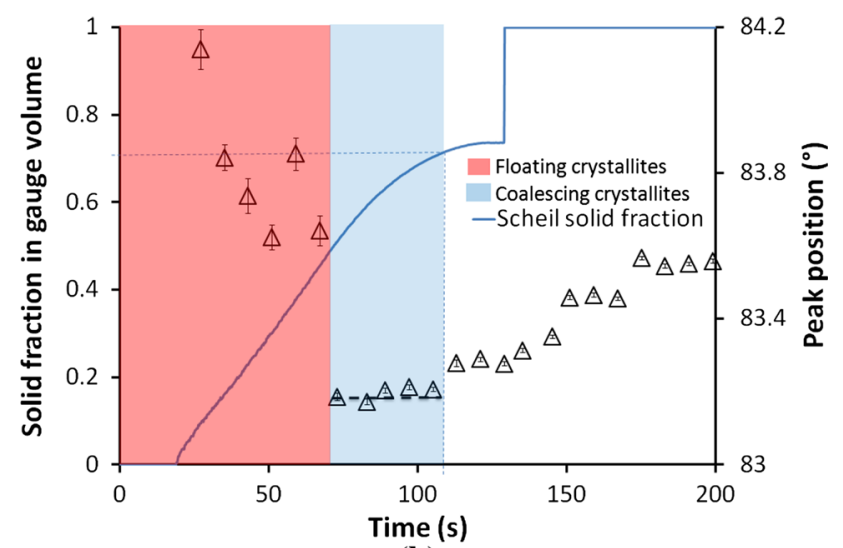

(b)

Fig. 4. Solid volume fraction in gage volume and peak position in (a) Sample 1 and (b) Sample 2. this temperature is uneasy as very few peaks are present. Nevertheless, it seems that the coherency temperature is around $584^{\circ} \mathrm{C}$ for Sample 1 and $592^{\circ} \mathrm{C}$ for Sample 2. After a certain time, the diffraction angle (peak position) starts to increase. This denotes the instant when the structure reaches its rigidity point and becomes able to sustain tensile straining. Rigidity temperature corresponds to the eutectic temperature, $548^{\circ} \mathrm{C}$ in Sample 1, i.e., during the formation of the eutectic (solid volume fraction increasing from $71 \%$ to $100 \%$ ). In Sample 2, rigidity temperature is $557^{\circ} \mathrm{C}$ (solid volume fraction around $71 \%$ ) above the eutectic temperature; i.e., rigidity is reached before the eutectic formation. Coalescence is schematically presented in the blue area in Figs. 3 and 4. During the transition, peak positions and thus lattice spacing are relatively constant. Small variations are due to thermal contraction and copper segregation. Coalescence starting at the coherency temperature and ending at the rigidity temperature lasts about $20 \mathrm{~s}$ in Sample 1 and $40 \mathrm{~s}$ in Sample 2. Experimental results are summarized in Table I.

Optical and binarized micrographs, presented in Figs. 5 and 6, show the presence of small grains $(\sim 100 \mu \mathrm{m})$ surrounded by a fine intergranular eutectic structure in both samples. In Sample 1, the grains are dendritic with secondary arm spacing of about $20 \mu \mathrm{m}$. In Sample 2, the grains are more globular and it is difficult to determine the secondary arm spacing. The binarized images reveal also that the grains are more percolated, i.e., bridged together, in Sample 2, whereas the eutectic phase is isolated in between the grains. In contrast, in Sample 1 where hot tears appeared, the grains are much less percolated but instead the eutectic phase is. Microporosity is also found in this sample (cf. Fig. 5) close to the surface of the casting.

These findings agree with previous studies on hot tearing. Terzi et al..$^{5}$ and Sistaninia et al. ${ }^{15}$ reported that the mechanical instabilities of micropores at the surface of the sample lead to the formation of hot tears. Hot tearing at the hot spot in Sample 1 is explained by a delayed coalescence that starts at a lower coherency temperature and ends with the eutectic formation. This situation is similar to the barium-treated alloys studied by Fallet et al. ${ }^{10}$

To determine strains, strain rates, and stresses once rigidity is reached, the experiments need to be conducted in a free-to-contract configuration to measure the evolution of the lattice parameter with decreasing temperature. The difference in peak positions between the constrained and free-to-con-

Table I. Experimental findings for Samples 1 and 2

\begin{tabular}{|c|c|c|c|c|c|}
\hline Sample & $\begin{array}{l}\text { Solidification } \\
\text { time (s) }\end{array}$ & $\begin{array}{c}\text { Coherency } \\
\text { temperature }\left({ }^{\circ} \mathbf{C}\right)\end{array}$ & $\begin{array}{c}\text { Rigidity } \\
\text { temperature }\left({ }^{\circ} \mathrm{C}\right) \\
\end{array}$ & $\begin{array}{c}\text { Coalescence } \\
\text { time }(\mathbf{s}) \\
\end{array}$ & Hot tears \\
\hline 1 & 40 & 584 & 548 & 20 & Tiny hot tears \\
\hline
\end{tabular}




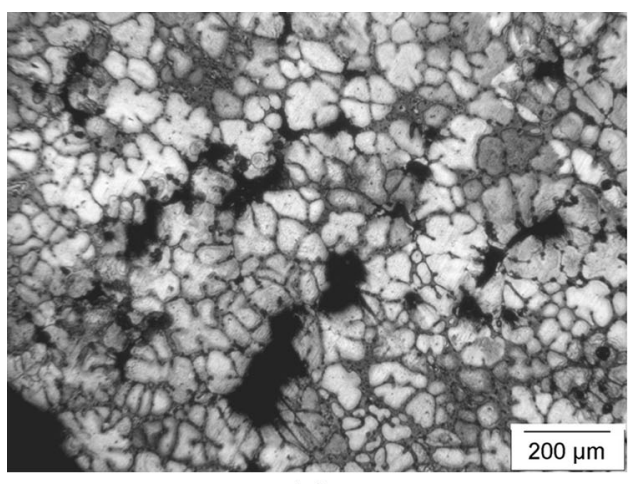

(a)

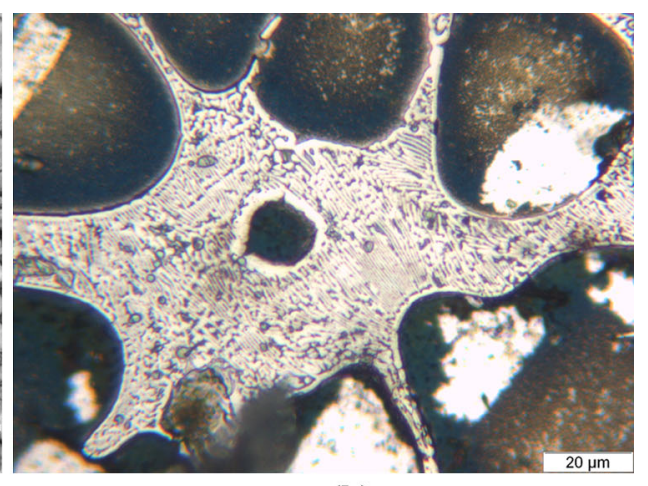

(b)

Fig. 5. Micrographs of Sample 1 exhibiting (a) micropores and (b) intergranular eutectic.

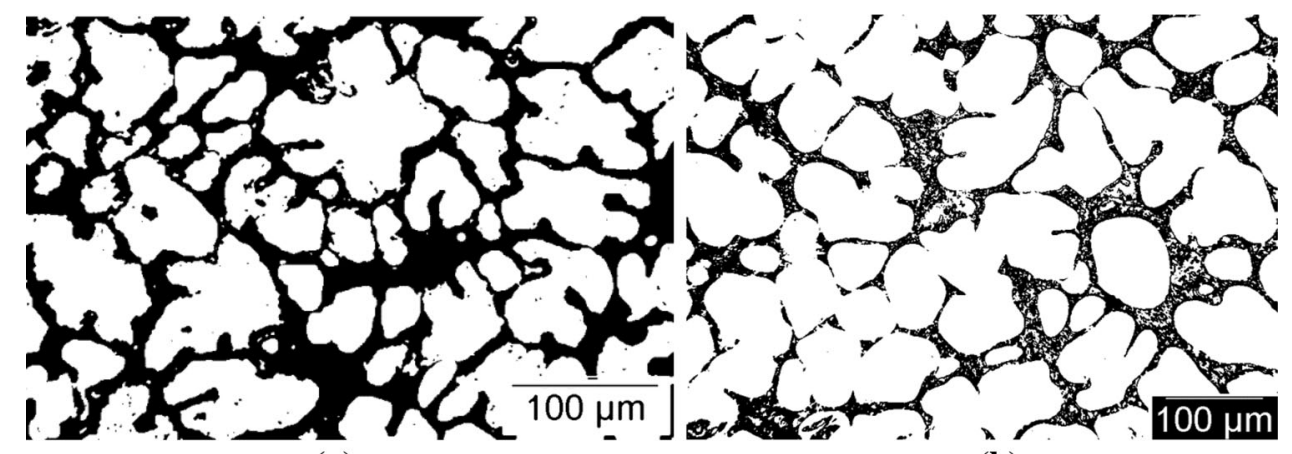

(a)

(b)

Fig. 6. Binarized micrographs of (a) Sample 1 exhibiting isolated primary phase grains and (b) Sample 2 showing percolated primary phase grains.

tract configurations will allow for calculation of the stress and strain built up in sound samples. These quantities will then be used to determine the alloy rheology in the as-cast state.

\section{CONCLUSION}

Neutron diffraction has been used to determine coherency and rigidity points, i.e., the coalescence transition, in solidifying aluminum alloys. Using a large detector is a prerequisite to obtain enough diffraction peaks in the semi-solid state. Rigidity temperatures of $557^{\circ} \mathrm{C}$ and $548^{\circ} \mathrm{C}$, depending on the cooling rate, have been determined for the grainrefined $\mathrm{Al}-13 \mathrm{wt} . \% \mathrm{Cu}$ alloy. At a high cooling rate, rigidity is reached during the formation of the eutectic phase and the solid phase is not sufficiently coalesced, i.e., strong enough, to avoid hot tear formation. The next step is to repeat the experiments in a free-to-contract configuration to measure the lattice parameter with decreasing temperature and to calculate the stress and strain built up in sound samples. With a better time resolution, the determination of coherency and rigidity points should be feasible in experimental conditions closer to the industrial ones, i.e., at higher cooling rates. X-ray diffraction experiments will be investigated as they might be an interesting alternative.

\section{ACKNOWLEDGEMENTS}

The authors express their deep acknowledgements to the Swiss National Science Foundation, Bern, for funding (Project No. 200021_146879) and the International Neutron Source at ILL-Grenoble for the provision of beam time.

\section{REFERENCES}

1. J.A. Danzig and M. Rappaz, Solidification, Part III, Defects (Lausanne, Switzerland: EPFL Press, 2009).

2. M. Rappaz, A. Jacot, and W.J. Boettinger, Metall. Mater. Trans. A 34, 467 (2003).

3. M. Rappaz, J.-M. Drezet, and M. Gremaud, Metall. Mater. Trans. A 30, 449 (1999).

4. A. Stangeland, A. Mo, M. M'Hamdi, D. Viano, and C. Davidson, Metall. Mater. Trans. A 37, 705 (2006).

5. S. Terzi, L. Salvo, M. Suery, N. Limodin, J. Adrien, E. Maire, Y. Pannier, M. Bornert, D. Bernard, and M. Felberbaum, Scripta Mater. 61, 449 (2009).

6. M. Suéry, S. Terzi, B. Mireux, L. Salvo, J. Adrien, and E. Maire, JOM 64, 83 (2012).

7. A.B. Phillion, R.W. Hamilton, D. Fuloria, A.C.L. Leung, P. Rockett, T. Connolley, and P.D. Lee, Acta Mater. 59, 1436 (2011).

8. C.M. Gourlay, A.K. Dahle, T. Nagira, N. Nakatsuka, K. Nogita, K. Uesugi, and H. Yasuda, Acta Mater. 59, 4933 (2011).

9. E. Giraud, M. Suéry, and M. Coret, Metall. Mater. Trans. A 41, 2257 (2010).

10. A. Fallet, G. Chichignoud, C.L. Martin, M. Suéry, and P. Jarry, Mater. Sci. Eng. A 426, 187 (2006).

11. J.-M. Drezet, A. Evans, T. Pirling, and B. Pitié, Int. J. Cast Met. 25, 110 (2012). 
12. M. Lalpoor, D.G. Eskin, and L. Katgerman, Metall. Mater. Trans. A 40, 3304 (2009).

13. J.-M. Drezet and T. Pirling, J. Mater. Process. Technol. 214, 1372 (2014).
14. T. Pirling, G. Bruno, and P.J. Withers, Mater. Sci. Forum 524-525, 217 (2006).

15. M. Sistaninia, S. Terzi, A.B. Phillion, J.-M. Drezet, and M. Rappaz, Acta Mater. 61, 3831 (2013). 